mystery 'envelops the mechanism of migraine'.

J. R. FOZARD

AND J. A. GRAY*

Preclinical and *Clinical Research, Sandoz Ltd, 4002 Basel, Switzerland.

\section{References}

1 Brewerton, T. D., Murphy, D. L. Mueller, E. A. and Jimersan, D. C. (1988) Clin. Pharmacol. Ther. 43, 605-609

2 Fozard, I. R. (1982) in Drugs and Platelets (Van Zwieten, P. A. and Schönbaum, E., eds) (Progress in Pharmacology Vol. 4), pp. 135-146, Fischer

3 Fozard, J. R. (1985) in Vascular Neuroeffector Mechanisms (Bevan, J. A. et al., eds), pp. 321-328, Elsevier

4 Kimball, R. W., Friedman, A. P. and Vallejo, E. (1960) Neurology 10, 107-111

5 Curzon, G., Barrie, M. and Wilkinson, M. I. P. (1969) I. Neurol. Neurosurg. Psychiatry 32, 555-561

6 Nappi, G., Savoldi, F., Bono, G. and Martignoni, E. (1979) Headache 19, 273-277

7 Carroll, J. D. and Hilton, B. P. (1974) Headache 14, 149-156
8 Del Bene, E. et al. (1977) in Headache: New Vistas (Si-uteri, F., ed.), pp. 101109, Biomedical Press

9 Hoyer, D. and Schoeffter, P. (1989) Br. J. Pharmacol. 96, 9P

10 Hoyer, D. (1989) in The Peripheral Actions of 5-Hydroxytryptamine (Fozard, J. R., ed.). pp. 72-99. Oxford University Press

11 Palacios, J. M. and Dietl, M. M. (1988) in The Serotonin Receptors (Sanders-Bush. E., ed.), pp. 89-138, Humana

12 Kennett, G. A. and Curzon, G. (1988) Br. I. Pharmacol. 94, 137-147

13 Kennett, G. A. and Curzon, G. (1988) Psychopharmacology 96, 93-100

14 Kennett, G. A., Whitton, P., Shah, K. and Curzon, G. (1989) Eur. J. Pharmacol. 164, 445-454

15 Neill, J. C. and Cooper, S. J. Psychopharmacology (in press)

16 Neill, J. C. and Cooper, S. J. Br. I. Pharmacol. (Abstr.) (in press)

17 Cunningham, K. A., Callahan, P.M. and Appel, J. B. (1986) Psychopharmacoiogy 90, 193-197

18 Neill, J. C. and Cooper, S. J. (1989) Psychopharmacology 97, 213-218

19 Fozard, J. R. (1988) in The Management of Headache (Clifford Rose, F., ed.), pp. 97-114
20 Puatfield, R. (1986) Headache, Springer

21 Monro, P., Swade, C. and Coppen, A. (1985) Acta Psychiatr. Scand. 72 (Suppl. 320), 98-103

22 Van Nueten, J. M. (1984) in The Pharmacological Basis of Migraine Therapy (Amery, W. K., Van Nueten, J. M. and Wauquier, A., eds), pp. 19-35, Pitman

23 Cohen, M. L. and Fuller, R. W. (1983) Life Sci. 32, 711-718

24 Coher, M. L., Kurz, K. D. and Fuller R. W. (1987) Clin. Exp. Theory Pract. A9, 1549-1565

25 Conn, P. J. and Sanders-Bush, E. (1987) I Pharmacol. Exp. Ther. 242, 552-557

26 Winther, K. (1985) Cephalagia 5 (Suppl. 3), 402-403

27 Glover, V. and Sandler, M. (1989) Trends Pharmacol. Sci. 10, 1-3

28 Moskowitz, M. A. (1984) Ann. Neurol. 6. 157-168

29 Coughlin, S. R., Moskowitz, M. A. Antoniades, H. N. and Levine, L. (1981) Proc. Natl Acad. Sci. USA 78, 7134-7138

30 Coughlin, S. R., Moskowitz, M. A. and Levine, L. (1984) Biochem. Pharmacol. 33, 692-695

MK-212: 1-(6-chloro-2-

pyrazino)piperazine

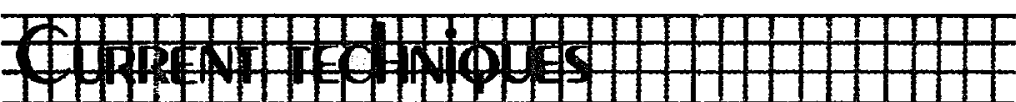

\title{
Identification of human serum cholinesterase variants using the polymerase chain reaction amplification technique
}

The polymerase chain reaction (PCR) is a newly developed technique for selectively amplifying RN $A$ or DNA sequences ${ }^{1}$ (see Box). Variations of the technique are proving to be powerful tools in fields as diverse as cancer and population biology. In pharmacology, PCR will allow rapid identification of point mutations or deletions of DNA responsible for variant forms or structural deficiencies in receptors and other proteins of pharmacological interest which are present in low abundance. It has already been useful in the analysis of mutations responsible for variants of human serum cholinesterase.

\section{Applications of PCR}

PCR amplification ${ }^{2,3}$ is a remarkably powerful technique. If the human genome were $1000 \mathrm{~km}$ long, and contained about 100000 genes, the average gene of $50 \mathrm{kbp}$ would occupy about $10 \mathrm{~m}$. A $300 \mathrm{bp}$ segment amplified by PCR would represent less than $10 \mathrm{~cm}$. The repeated cycles of annealing, primer extension and heat denaturation (see Box) are an extremely efficient process. Millions of copies of the selected segment are generated, and the amplified DNA can easily be seen in agarose gels stained with ethidium bromide. Regions of interest can be sequenced directly using specific sequencing primers. Alternatively, amplification primers can be constructed with synthetic restriction sites at their $5^{\prime}$ ends to allow the amplified segments to be inserted into suitable vectors, such as M13 phage, for single-strand sequencing ${ }^{4}$. This is particularly useful for long amplified segments and may also be advantageous in searching for new point mutations within heterozygous samples, where very clean DNA is needed to reduce confusion with shadow bands.

The major limitation of the PCR technique is a direct consequence of its remarkable sensitivity: contamination of the sample by even minute amounts of any DNA recognized by the amplification primers can result in very efficient amplification of the unwanted material. Precautions must be taken to reduce the possibilities for contamination as much as possible, and controls (without template DNA) must be included routinely.

PCR can be used for the analysis of DNA mutations that cannot readily be detected in any other way (for example, mutations producing an alternative codon for the same amino acid, so that the enzyme is unchanged). Quantitative structural variants may result from mutations affecting the half-life of the enzyme, without producing any changes in the quality of its catalytic activity. In fact, it may be impossible to identify these variants by any test based upon kinetic properties, such is a response to competitive inhibitors. PCR also provides a simple means of diagnosing such alleles in heterozygous individuals. Presumably, a structural change confers greater instability, 


\section{Polymerase chain reaction}

The polymerase chain reaction (PCR) can be used to amplify selectively any DNA or RNA segment, as long as some sequence information is already known. Two oligonucleotide primers of $20-30$ bases are synthesized which are complementary to the $3^{\prime}$ ends of each strand of the target segment. These primers are mixed with the sample DNA, nucleotides and DNA polymerase. The mixture is heated to separate the DNA strands, and cooled to allow the primers to anneal with the target DNA. The polymerase then extends the primer, producing a strand complementary to the target. The cycle is repeated several times, doubling the amount of the target segment each time.

The choice of primers determines the length of the amplified segment: when primer binds to original template, it is extended unidirectionally for an indeterminate length. However, when the second primer binds to this newiy synthesized DNA, it will be extended only to the end of the DNA fragment - that is, to the position of the first primer (see Fig.). The polymerase used in PCR is the heat-stabie Taq polymerase isolated from Thermus aquaticus. This enzyme has two advantages: it is active at high temperatures, allowing more specific annealing conditions, and giving greater efficiency and specificity of reaction; and it withstands the higher temperatures required for denaturation of the DNA, so that it need be added only at the beginning of the process, rather than after each cycle.

In a typical amplification protocol, the template DNA is denatured at $94^{\circ} \mathrm{C}$ for $1-2 \mathrm{~min}$, annealed with the primers at $55^{\circ} \mathrm{C}$ for about $2 \mathrm{~min}$, and primer extension occurs at $72^{\circ} \mathrm{C}$ for $1-2 \mathrm{~min}$. Repeating these steps 20-30 times, which takes airout $2 h$, can amplify the target DNA segment several millionfold. Commercial, programmable cyclers are available, so that optimal conditions can be selected for each application.

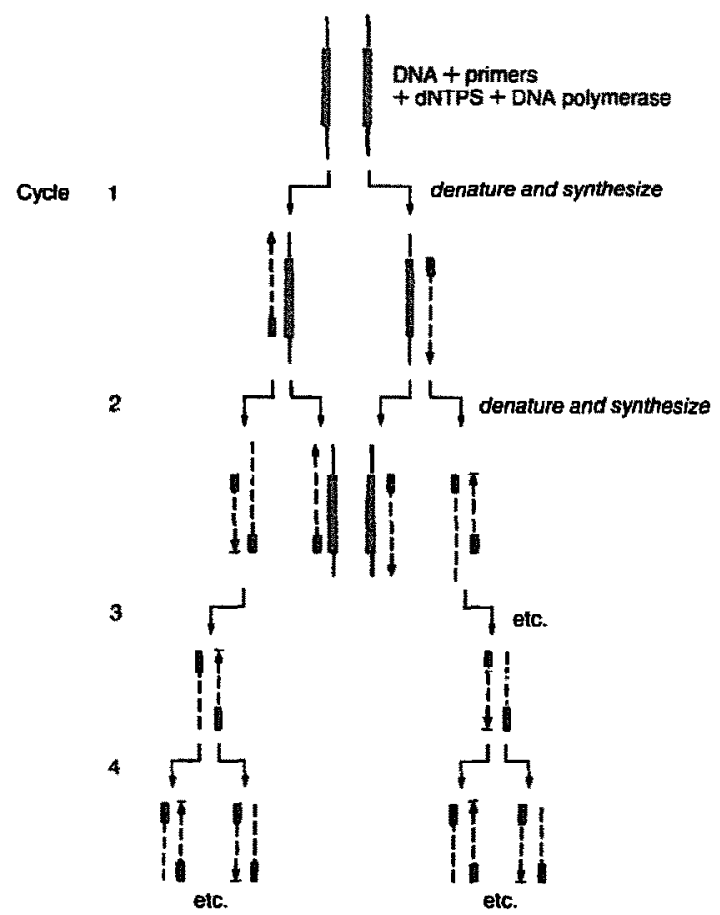

Fig. DNA amplification by PCR. Note that after the first two cycles, the fates of the original DNA and extension products made from it are not shown. Target sequence (E); PCR primer (1)): new DNA (-). (Reproduced from Trends Genet., June 1989, center-page diagram.) or faster turnover, on the protein, and the steady-state level of the variant enzyme is reduced. Careful studies of kinetic properties, even heat denaturation experiments, may fail to reveal phenotypic differences between the variant and usual enzymes.

New methods are being developed using PCR-amplified DNA to diagnose mutations without sequencing the DNA each time, and simplify the detection of certain mutations. Since multiple PCR amplifications of different genomic DNA segments can be carried out simultaneously in the same tube, this approach has been particularty useful for diagnosing several different types of deletion mutation in patients with Duchenne muscular dystrophy ${ }^{5}$. Selective hybridization conditions for the amplified DNA with allelespecific oligonucleotide probes have been developed in many laboratories. To avoid the use of radioactive primers, allele-specific primers can be coupled with indicator enzymes, such as horseradish peroxidase. This technique is used for prenatal diagnosis of sickle cell disease with amplified DNA from fetal cells ${ }^{6}$, and for identifying carriers of the disease. In other methods, the PCR-amplified fragments are separated on denaturing gradient polyacrylamide gels; in about half of all cases, a single base change in a fragment of between $50 \mathrm{bp}$ and about $1000 \mathrm{bp}$ results in a detectable change in the mobility of the fragment ${ }^{7}$.

The PCR amplification method is gaining wide application in the analysis and diagnosis of many hereditary conditions'. New, improved allele-specific detection systems are developing rapidly. These technical advances offer unusual opportunities for study of hereditary traits associated with abnormal responses to drugs and environmental chemicals (pharmacogenetics) non-invasively (except to obtain a small sample of blood DNA). This applies to all pharmacogenetic conditions those due to differences in enzymes directly involved in pharmacokinetics and drug metabolism, and those caused by modified drug receptors and specialized proteins regulating drug effects at the pharmacodynamic level. Our studies on human serum cholinesterase variants provide an example of the use of this approach.

\section{Human serum cholinesterase}

Analysis of cholinesterase variants by the PCR reaction ${ }^{8}$ followed many years of basic work on the purification and characterization of serum cholinesterase and its variants. The 'atypical' (dibucaineresistant) form of human serum cholinesterase with reduced affinity for choline ester substrates, particularly succinylcholine, was discovered in 1957 (Ref. 9). Since then, several additional qualitative and quantitative variants have been identified, including 
some 'silent' variants with no detectable enzymatic activity. Most of these variants, alone or in combination, cause a prolonged duration of action of the drug succinylcholine, which is still commonly used as an adjunct in surgical anesthesia to obtain greater muscular relaxation. The pharmacogenetic importance of cholinesterase variants has, thus, been recognized for many years ${ }^{10}$, but no definite physiological role for serum cholinesterase (EC 3.1.1.8, butyrylcholinesterase, pseudocholinesterase, nonspecific cholinesterase) has been established.

Human serum cholinesterase is a glycoprotein ( $~ 24 \%$ carbohydrate) present primarily as a tetramer of $\sim 342 \mathrm{kDa}$. Each of the identical subunits contains 574 amino acids and one active site. The subunits are held together by two interchain disulfide bridges and by hydrophobic, non-covalent forces ${ }^{11}$. The average amino acid sequence of the enzyme isolated from plasma pooled from many unrelated people ${ }^{12}$ was identical with the sequence deduced from cDNA clones isolated from an infant brain cDNA library ${ }^{13,14}$. Thus, we conclude that human brain cholinesterases and that of human liver (the probable source of serum cholinesterase) are products of the same gene.

A number of tests using selective inhibitors such as dibucaine ${ }^{9}$ and fluoride ${ }^{15}$ have been developed to identify the cholinesterase variants. The ease of obtaining serum samples from patients who experience a prolonged response to succinylcholine has facilitated the development of diagnostic tests to characterize the altered properties of variant cholinesterases. Sera from closely related family members permitted detailed pedigree analyses and deduction of the inheritance patterns of these genetic traits. As expected, a simple, autosomal inheritance of the variant cholinesterases was found. The $E_{1}$ locus, which determines the structural quality of cholinesterase, is located in the q21-qter region of chromosome 3 (Refs 16 and 17); it is closely linked to trainsferrin.

\section{Analysis of variants at DNA level}

For most of the past 20 years, the dibucaine inhibition number, fluoride inhibition number and level of serum cholinesterase activity have been sufficient measures to identify most of the known cholinesterase phenotypes associated with succinylcholine sensitivity. During the last decade, however, several additional rare and common variants of the enzyme have been discovered, and at least ten distinctive variants are now known (Table I). Many of these are quantitative variants, with normal kinetic properties, as far as can be told from the standard tests ${ }^{18}$. The increased number of possible phenotypes (28 phenotypes fromi ten alleles) has complicated the old system used for identifying phenotypes. In some instances, phenotypes conferring sensitivity to succinylcholine are easily confused with phenotypes that give a normal drug response. Clearly, a DNA structural basis for cholinesterase phenotyping would be holpful, as well as being a logical frame of reference for developing future diagnostic methods to distinguish the important new phenotypes.

Cholinesterase is present in human serum in very low concentration ( $\left.\sim 5 \mathrm{mg} \mathrm{l}^{-1}\right)$. Thus, it has been impractical to purify the variant enzymes and directly identify structural differences in amino acid composition. We undertook cloning the gene for cholinesterase for three reasons: (1) to identify the structural alterations responsible for the variant forms of the enzyme; (2) to establish a structural basis for the classification of these variants, including the quantita- tive variants that cannot be identified by any of the standard inhibitor or kinetic tests; and (3) to learn more about the genetic relationships between cholinesterases and the acetylcholinesterases, and other 'serine-type' esterases.

The atypical (dibucaine-resistant) cholinesterase variant is the one most commonly associated with succinylcholine sensitivity. Our approach ${ }^{8}$ involved deternining the amin $>-$ id sequence of the usul cholinesterase, an this in ismation to construrt suitable difonicleotic $\Rightarrow$ rues to screen for and so.j e CDNA clones elcodin ? . nestin inse from individuals hor..ozygous for the usual enzyme. These sequences were compared with nucleotide sequences from white blood cell genomic library clones from a homozygous atypical individual. The amino acid citeration(s) in the atypical protein could then be deduced.

We found just one nucleotide difference among the 1722 bases representing the coding region of the mature atypical protein: a point mutation at nucleotide 209 (GAT to GGT), which changes codon 70 from aspartate to glycine ${ }^{8}$. The resulting change of a single acidic amino acid to a neutral amino acid seems to be a reasonable explanation for the reduced binding affinity of succinylcholine at the anionic site of the atypical enzyme. However, it was necessary to verify that the point mutation in nucleotide 209 segregated

TABLE I. Genetic forms and variants of human serum cholinesterase

\begin{tabular}{|c|c|c|}
\hline Name and characteristics & Frequency & Pef. \\
\hline $\begin{array}{l}\text { Usual } \\
\text { K-variant (quantitative; activity reduced } \sim 30 \% \text { ) (Ala539 } \rightarrow \text { Thr) } \\
\text { Atypical (dibucaine-resistant) (Asp70 } \rightarrow \text { Gly) } \\
\text { Silent (no, or veny low activity) (several types: Silent-1 = } \\
\text { Gly } 117 \rightarrow \text { frame-shift) } \\
\text { Fluoride-resistant } \\
\text { J-variant (quantitative variant; activity reduced } \sim 70 \% \text { ) } \\
\text { H-variant (quantitative variant; activity reduced 90\%) } \\
\text { Newfoundland } \\
\text { Cynthiana (high activity) } \\
\text { German family high activity variant } \\
\text { South African variant (high actlvity) }\end{array}$ & $\begin{array}{c}0.854 \\
0.125 \\
0.017 \\
1 \times 10^{-5} \\
6.6 \times 10^{-6} \\
\text { rare } \\
\text { rare } \\
\text { rare } \\
\text { four familes } \\
\text { two families } \\
\text { one family }\end{array}$ & $\begin{array}{c}\mathbf{f} \\
\mathbf{g}, \mathbf{h} \\
\mathbf{j} \\
\mathbf{j} \\
\mathbf{k}, \mathbf{l} \\
\mathbf{m} \\
\mathbf{n}\end{array}$ \\
\hline
\end{tabular}

-Rubinstein H. M. et al. (1978) J. Med. Genet. 15, 27-29; Whittaker, M. and Britten, J. J. (1985) Hum. Hered. 35, 364-368; CKalow, W. and Staron, N. (1957) Can. J. Biochem. Physiol. 35. 1305-1320; "Kalow, W. and Gunn, D. R. (1959) J. Pharmacol. Exp. Ther. 120, 203-214; -Liddell, J. et al. (1962) Nature 193, 561-562; 'Harris, H. and Whittaker, M. (1961) Nature 191. 496-498; ${ }^{\circ}$ Garry, P. et al. (1976) J. Med. Genet. 13, 38-42; " Evans, R. T. and Wardell, J. (1984) J. Med. Genet. 21, 99-102; 'Whittaker, M. and Britten, J. J. (1987) Hum. Hered. 37, 54-58; ISimpson, N. E. and Elliott, C. R. (1981) Am. J. Hum. Genet. 33, 366-374; 'Neitlich, H. W. (1966) J. Clin. Invest. 45, 380-387; 'Whittaker, M. (1986) Cholinesterase, Karger; m. Welbruck, A. and Henkel, E. (1979) Eur. J. Biochem. 99, 65-69; "Krause, A. et al. (1988) J. Med. Genet. 25, 677-681 


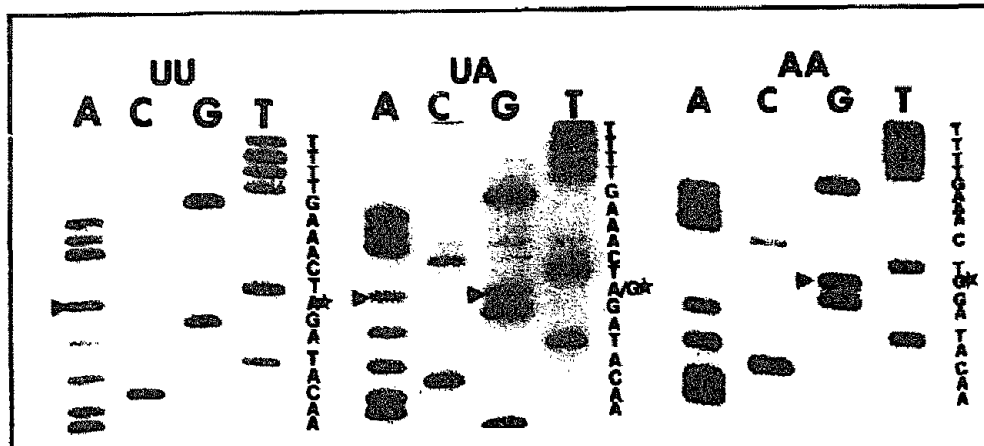

Fig. 1. DNA sequences of usual (UU), heterozygous (UA) and atypical (AA) cholinesterases showing the nucleotide substitution in the atypical cholinesterase sequence. Genomic DNA from three individuals was amplified by the PCR technique and sequenced. The $U$ and $A$ alleles were identical except for the nucleotide indicated by an asterisk. Codion 70 is GAT in UU, GAT and GGT in UA, and GGT in AA. (Reproduced from Ret. 2 with permission.)

in the expected manner among family members of several pedigrees with atypical cholinesterase, and to analyse unrelated individuals carrying the atypical cholinesterase trait. For such studies, we needed a simpler method than making individual genomic DNA libraries, screening each of them for the right clones, and then sequencing the DNA in the suspected region to look for the point mutation.

\section{Polymerase chain reaction}

The polymerase chain reaction. permitted the selective amplification of a small segment (187 bp) of genomic white blood cell DNA including the nucleotide 209 region (Fig. 1). Sequencing of the amplified DNA revealed complete concordance between the nucleotide base at position 209 and the serum cholinesterase phenotype (usual, usual-atypical or atypical) in every individual tested ${ }^{8}$.

Another special advantage of the PCR amplification technique is that, in DNA from heterozygous individuals, the sequences representing the usual and atypical alleles are both amplified; sequencing gels show both the mutant and 'wild-type' nucleotide bases at the level of the point mutation. The speed and convenience of the PCR analysis permitted us to sequence the region of interest in many individuals within a few weeks, and verify that the DNA sequences accurately predicted the serum cholinesterase phenotypes.

Since the location of introns (nucleotide positions $-93,1433$ and 1600), and the sequences of short segments of intron DNAA adjacent to the intron-exon junctions were known, three pairs of amplification primers were designed which could amplify the entire coded region of cholinesterase as three segments (Fig. 2). The largest of these ( 1500 bases), which includes exon 2 , could be sequenced directly with a series of sequencing primers spaced about $250 \mathrm{bp}$ apart. Thus, the entire coding region can be amplified and sequenced using the PCR amplification technique, from the DNA obtained from small amounts (a few $\mathrm{ml}$ ) of blood. This has made it practical to search for structural mutations underlying the other variants of cholinesterase.
- A frame-shift mutation at Gly117 (GGT to GGAT) has been identified as the basis for one type of silent (i.e. no enzyme activity) mutation in two unrelated families $^{\mathrm{B}}$.

- Another point mutation changing Thr243 to Met (ACG to ATG) segregates with the fluorideresistance trait in two members of one family ${ }^{3}$; however, this explanation of the fluoride variant will remain provisional until it has been observed in other fluoridevariant families.

- A threonine-alanine polymorphism has been detected at position 539 which depends upon the nucleotide at position 1615 (GCA/ACA, Ala/Thr; allele frequency $0.875 / 0.125)^{19}$. We suspect that the less common allele coding for Thr represents the quantitative K-variant, which is characterized by a reduction of about one-third in cholinesterase activity. This hypothesis is supported by the observation that in individuals with the atypical allele (Gly at position 209), which tends to be inherited in tandem with the less common allele for Thr539 (Ref. 19), the average level of serum cholinesterase is about one-third that of normal individuals, when measured immunologically ${ }^{20}$.

Several additional potential polymorphic sites are being evaluated in larger numbers of DNA samples using PCR. This will permit detailed linkage studies within the cholinesterase gene, and allow

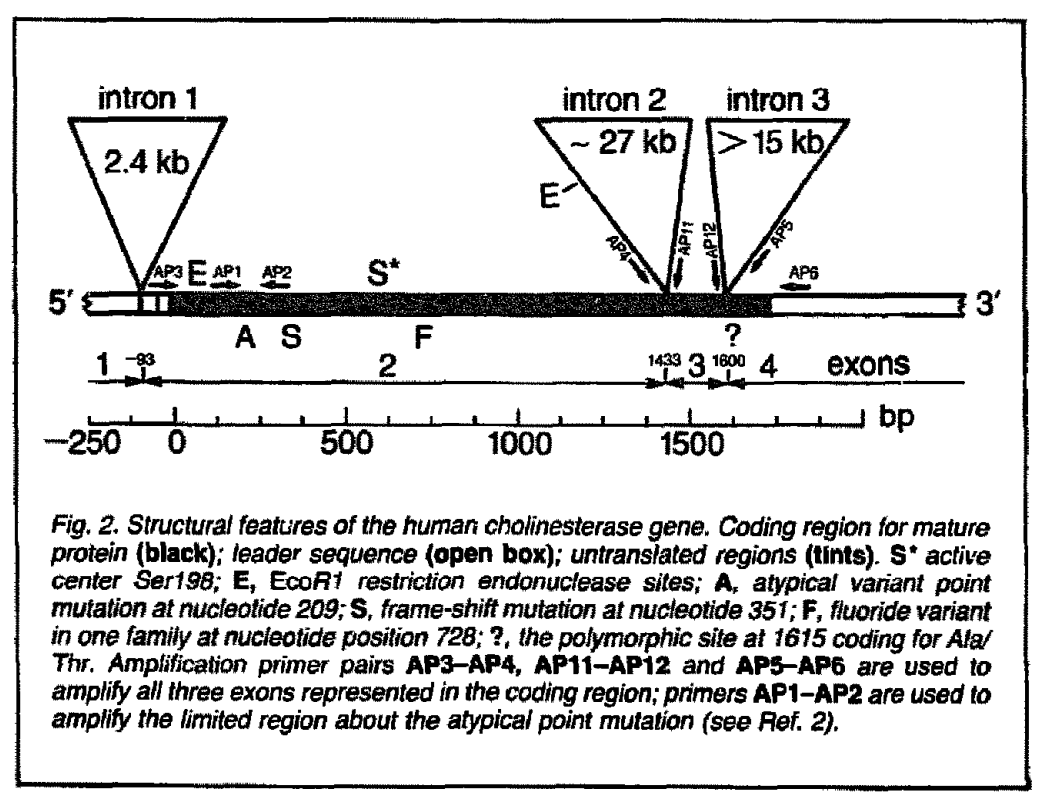


high resolution of these closely linked markers, to determine how various combinations of these structural alternatives influence the properties and concentration of serum cholinesterase.

\section{Acknowledgement}

Support of NIH grant 27028 is gratefully acknowledged.

BERT N. LA DU

Department of Phammacology, University of Michigan Medical School, Ann Arbor, MI 48109-0626, USA.

\section{References}

1 White, T. J., Arnheim, N. and Erlich. H. A. (1989) Trends Genet. 5, 185-189 2 Saiki, R. K. et al. (1988) Science 239. $487-491$
3 Erlich, H. A., Gelfand, D. H and Saiki, R. K. (1988) Nature 331, 461-462

4 Ginsburg, D. et al.(1989) Proc. Natl Acad. Sci. USA 86, 3723-3727

5 Chamberlain, ]. S. et al. (1988) Am. I. Hum. Gentet. 43 (Suppl.), A178

6 Saiki, R. K. et al. (1988) New Engl./. Med. $319,537-541$

7 Sheffield, V. C., Cox, D. R. Lerman, L. 5. and Myers, R. M. (1989) Proc. Natl Acad. Sci. USA 86, 232-236

8 McGuire, M. C. et al. (1989) Proc. Natl Acad, Sci. USA 86, 953-957

9 Kalow, W. and Genest, K. (1957) Can. J. Biochem. Physiol. 35, 339-346

10 Kalow, W. (1962) Phamacogenetics: Heredity and the Response to Drugs, Saunders

11 Lockridge, O., Eckerson, H. W. and La Du, B. N. (1979) J. Biol. Chem. 254, 8324-8330

12 Lockridge, O. et al. (1987) / Biol Chem. $262,549-557$

13 McTiernan, C. et al. (1987) Proc. Natl
Acad. Sci. USA 84, 6682-6686

14 Prody, C. A., Zevin-Sonkin, D., Gnatt, A., Goldberg, O. and Soreq, H. (1987) Proc. Natl Acad. Sci. USA 84, 3555-3559

15 Harris, $H$. and Whittaker, M. (1961) Nature 191, 496-498

16 Yang, F. et al. (1984) Proc. Natl Acad. $5 \mathrm{ci}$. USA 81, 2752-2756

17 Soreq, H., Zamir, R., Zevin-Sonkin, D. and Zakut, H. (1987) Hum. Genet. 77, 325-328

18 Whittaker, M. (1986) Cholinesterase, Karger

19 Bartels, C. F. Van der Spek, A. Lockridge, O. and La Du, B. N. (1989) FASEB [. 3, A741

20 Eckerson, H. W., Oseroff, A., Lockridge, O. and La Du, B. N. (1983) Biochem. Genet. 21, 93-108

Next month TiPS will be publishing an article on the use of PCR in the study of membranebound receptors.

\section{This and That: exotic foods - prophylaxis and peril}

EVER NEW MODES of conspicuous consumption evolve to soak up disposable, or surplus, income. The Japanese habit of eating raw fish in the form of sushi or sashimi has become common enough in the United States to have achieved the status of an editorial in the New England Journal of Medicine ${ }^{1}$. This was provoked by a report of a $4.2 \mathrm{~cm}$ long bright red worm crawling out of the surgical incision in a patient undergoing surgery for apparent acute appendicitis $^{2}$. The worm was identified as an Eustrongylides, a common parasite of fish-eating birds, and had presumably been swallowed by the patient during a sushi-eating session a few days earlier. The authors warn illiterately that 'perforation of the stomach or intestine by the invading larva may present as an acute abdomen'.

This is but the latest in an increasing number of reports on the parasitic dangers of consuming raw fish. Brookes may eulogize the fish that 'ripples with dark ecstasies' in its smooth curving world, but the fact is that fish lead a wormridden existence, and are more likely to be rippling with parasiteinduced discomfort. Over $80 \%$ of Pacific salmon and red snapper are infested with Anisakis ${ }^{3}$. Most Atlantic cod and plaice is infested. Indeed, as the parasitic principle enunciated by Jonathan Swift in the jingle quoted below reminds us, to be infested with parasites is the natural state of mammals. This is a reality we lose sight of in our urban existence of sanitized toilet seats, chlorinated water and pillchoked cabinets. One has only to recall 'Queeney' Thrale, daughter of an upper middle class English family friendly with Samuel Johnson. Her life bridged the 18th and 19 th centuries. She was a lifelong sufferer from roundworms, treated unavailingly with tin pills and senna pods ${ }^{4,5}$.

So, naturalists observe, a flea Hath smaller fleas that on him prey;

And these have smaller fleas to bite 'em

A 'natural' existence is short and uncomfortable, and public health problems erupt whenever we forget this. And, in the increasing habit of eating raw fish in the form of sushi, sashimi, ceviche, lomi lomi, or sunomono, we are forgetting this. The biggest risk appears to be anisakiasis. Anisakis, commonly called roundworm, has a life
And so proceed ad infinitum history in which it passes through fish and/or crustaceans and squid and on through marine mammals to complete its cycle ${ }^{6}$. Anisakiasis is common in Japan and is increasing in North America, over $70 \%$ of the reported cases occurring since $1980^{3,7}$. In an interesting application of the law of ecology which states that everything is connected to everything else, one factor in the increase in the Pacific states appears to be the Marine Mammal Protection Act of 1972, which has led to increased populations of sea mammals and a resulting increase in the percentage of fish associated with them that become infested.

The roundworm has a boring tooth, and can tunnel into intestinal walls, with serious consequences. Anisakiasis is commonly misdiagnosed as appendicitis, Crohn's disease, gastric ulcer or cancer - a situation helped by the absence of parasites or eggs in the feces. Thus, in one large Japanese series, $37 \%$ of cases ultimately found to be anisakiasis were initially diagnosed as gastric cancer, and another $16 \%$ as appendicitis ${ }^{8}$. The worms may be coughed up after ingestion, or produce the 'tingling throat' syndrome as they wriggle in the esophagus. Antihelminthics are without effect, and surgical resection is the only effective treatment, as in a recent case where there was penetration of the 